Academic City University College - Accra Ghana

Society for Multidisciplinary \& Advanced Research Techniques (SMART) Africa

Tony Blair Institute for Global Change

FAIR Forward - Artificial Intelligence for All - Deutsche Gesellschaft für Internationale Zusammenarbeit (GIZ) GmbH

Accra Bespoke Multidisciplinary Innovations Conference (ABMIC)

\title{
Leadership, Strategy and Organizational Change
}

\author{
Dr. Michael Ba Banutu-Gomez \\ Professor, Rowan University \\ Glassboro, New Jersey, USA \\ Banutu-gomez@rowan.edu \\ Phone: +1856-256-5425
}

Ramatoulie Whan

Research Assistant, Banutu Business College

Lamin Kombo North

The Gambia

\section{Member Proceedings Citation Format}

Michael Ba Banutu-Gomez \& Ramatoulie Whan (2021): Leadership, Strategy and Organizational Change. Proceedings of the Accra Bespoke Multidisciplinary Innovations Conference. University of Ghana/Academic City University College, Accra, Ghana. December, 2021. Pp 1-10 www.isteams.net/ghanabespoke2021. DOI - https://doi.org/ 10.22624/AIMS/ABMIC2021P1 


\title{
Leadership, Strategy and Organizational Change
}

\author{
Michael Ba Banutu-Gomez \& Ramatoulie Whan
}

\begin{abstract}
This study examined the role of leadership in organizational change. The researcher stated that the role leader's play in the strategy process would have a significant impact on the overall success of any type of organizational change. The researcher found that leaders play a huge role when dealing with any type of organizational change implementation. A leader must take into consideration and utilize effective communication with the organization throughout this process. Further, this research revealed a four step that would make change successful in an organization. It is vital for a leader to utilize good leadership style, and empathy for employees throughout a change and maintain positive culture. This research has revealed that leader plays a very important role in organizational change and must take all of that into consideration for an effective transition and successful change to come to reality in an organization.
\end{abstract}

Key Words: Leadership, Change, Strategy, Communication, Culture, and Teams

\section{INTRODUCTION}

Organizations today are operating in an extremely competitive, energetic and complex environment. This environment moves at an extremely fast pace and in order for organizations to stay relevant they need to keep up with the pace. This means change is inevitable. Successful organizations treat transformation as a critical piece in making sure they have a competitive advantage. So, what is the role of leadership in organizational change? Leadership is the key because transformation requires leadership. Because of their position and influence within an organization, leaders and managers are already in a good position to bring about change. The role leader's play in the change process will have a significant impact on the overall success of any type of organizational change.

\section{LITERATURE REVIEW}

Organizational Change Challenges

Mergers 101 is an article that focuses on how a manager should handle the change that comes with a merger or acquisition. Mergers and acquisitions cause abundant change, which can cause extreme stress amongst all employees. The article focuses on five key variables that will help during organizational change of this nature. These are communication, leadership and trust, organizational culture, change and stress. The article gives guidance to management to prepare them and gives them an approach to achieve success during a merger or acquisition.

\section{Strategic Organizational Change}

This article examines the sources of strategic organizational change. It can emanate from two different sources - the external environment (competitor's actions, government regulations, economic conditions, technological advances) or the internal environment (new mission or vision, new technology purchase, mergers, acquisitions or the decline of morale). 
It discusses the implications these changes have on management and how leadership, learning and motivation are all important factors. Change is an integrative process where both the soft resources (human) and hard resources (systems and technologies) need to be considered for the change to be successful. The largest barrier to change is not the technologies and work processes but involves people. This is why leadership, learning, motivation and productivity are so important.

Leadership and Organizational Communication in a Change Process

The article describes how leadership and communication within a change process are two of the most important factors during an organizational change. Additionally, the article provides various statements to where it is extremely important that the leader, as well as senior level management, effectively communicate the vision for the change and the change as a whole to drive the organization to success. Communication from leadership to employees is key, and the communication amongst employees must be effective as well, to help the organization effectively drive its change strategy. Often times, employees will be afraid over their roles and how their roles may change during the organizational change, or to what degree they have job security. Overall, it is extremely important for the leader, senior level management, and employees to effectively communicate to help drive the organizational change.

\section{Planned Organizational Change}

This article speaks primarily to the relationship senior managers have with leadership, and how a change must be properly planned and effectively communicated to leaders to help the organization be successful. Primarily focusing on communication and the means for which the organization communicates a need for change, the article speaks much to leaders having to know and explain the "why" behind organizational change. Many times, employees are comfortable within their roles, and could be resistant to change, which is why the vision must be clearly and effectively communicated. Additionally, this article focuses on the activities necessary for an organization to carry out planned organizational change, and the support necessary from employees and leadership to help the organization be successful. Planned Organizational Change can be of great benefit to an organization by following various different aspects and effective communication.

\section{Transformational Leadership and Organizational Change}

Transformational Leadership is the focus of this article. A transformation leader is one who is best suited to lead during times of organizational change. A transformational leader has the ability to change the outlook and behavior of his/her followers and can motivate them into downgrading self-interest for the good of the company. Transformational leaders instill confidence, create long-term solutions, and create enthusiasm for the new goals and vision of the company. They are charismatic and inspirational. Change is more successful when managed by a transformational leader.

The other type of leadership examined was Transactional leadership, which is a type of leadership that rewards desired work behavior and performance and works with the present culture of the organization. This type of leader is efficiency orientated and avoids risk-taking. Transformational leaders are more effective during periods of change because they are better equipped to handle a minor crisis and adjustments that occur during times of change. 


\section{Organizational Success}

Organizational Success is one of the largest outcomes as part of any organizational change. While many organizational change strategies focus on various aspects of the organization, they all aim to drive the organization toward success. The literature speaks primarily to the disconnect employees may feel from leadership and senior level management, not necessarily with regard to the change process as a whole, but to the outcomes and performance the change may bring the employees. It is extremely important for an organization to work effectively and efficiently within its change strategy, but it is also up to the employees to help drive the organization towards success, while also viewing their outcomes and performance based prior from the organizational change. This is one of the greatest aspects of an organizational change, and employees must be ensured that their effort and performance are linked to help benefit the organization throughout the organizational change.

\section{Organizational Culture Change}

Culture Change focuses on making changes in any industry where safety should be a priority. This article discusses a company lacking in proper safety issues and how change can be implemented to ensure workers are safe. The article points out that changing unsafe behavior in the workplace begins with leadership and organizational behaviors (candor, open communications, accountability, respect and sharing). This article relays the idea that unsafe behavior is a cultural change within an organization and to change the culture involves all aspects of the company - leadership, organizational and workforce. To implement changes in safety routines it is important for leaders to "lead by example" and to get the employees involved by letting them have some input.

\section{Continuous Organizational Change Process}

Organizations always need to change; just when one change is complete, another one is needed. The author relates it to the story of Moses and how the Hebrew were not happy in Egypt and as soon as Moses led them out, they started complaining about the desert and lack of food. The point to the article is that companies need leaders who are continuously inspired because there isn't just one change on the horizon; there will be many and leaders need to keep coming up with new ideas or companies need to get new leaders because if they do not the change process will break down pretty quickly.

\section{Models of Change Agency}

There are four different models of change agency are explored. The first being the "leadership model" where senior executives at the top of the organization envision and initiate the change. The second model is "management model" where middle-level management adapt, carry forward or build support for the change. The third model is the "consultancy model" where a consultant assists with the change by providing things like advice, expertise, and a project management plan to facilitate the change. The fourth model is "team model" where a group is formed to see the change to completion and this group can be composed of managers, employees from all levels and even external and internal consultants. Reviewing this article may help an organization decide which model would work best for them while going through organizational change. 
Leadership Excellence and Change Initiation

Appropriately, named "Let the Middle Lead" talks about how change is initiated from top management or at least "approved" by top management, but many times they are not close enough to the day-to-day operations to understand the types of changes that need to take place. Those who do know the types of change needed are in the middle, afraid to step on the toes of senior managers, so they say nothing. This article gives advice for those in the middle and how they can bring their ideas to senior management. Such as organize yourself to support senior management and let them know a group of you are gathering to brainstorm ideas on how to make the organization better and will keep supervisors informed. While working on new ideas be sure not to slack off on the current company agenda, hold meetings over lunch, and don't let them become gripe session. Some leaders may feel threatened by the middle taking the lead, but this is an excellent opportunity for leadership to unleash the talent below them. With proper leadership and support, this new group could give current management a competitive advantage and make them look good.

\section{Keys to Organizational Change}

Robert Clement writes how he believes the three keys to organizational change are culture, leadership and power. The first step is to deal with organizational culture because this is the hardest thing to change and cannot be changed quickly. He suggests working through the existing culture rather than trying to change the culture itself - the key understands the culture that already exists. Leadership and an effective use of power is more important than an attempt to change culture. Leadership from top management is a critical element. Studies have proven that managers themselves (not consultants) need to be the change agents. Managers "leading by example" have proven successful. Changes implemented gradually worked best as these allowed managers time to learn their new managerial skills. The third key is the need to deal with power and politics. Managers need to begin with an assessment of the company's history. They need to look at individuals and coalitions that have the greatest power. Stakeholders in the company need to be examined to determine who would block or support change. Power can be used in positive and negative ways.

\section{IMPACTS OF LEADERSHIP ON WORKPLACE CONFLICTS}

The literature examines three styles of leadership - transformational, transactional and laissezfaire and their effect on conflicts in the workplace. When a company is going through organizational change there is bound to be conflict between employees as change usually brings power issues. Transformational leaders stimulate and inspire their employees; transactional leaders motivate their employees by focusing on their personal interests and laissez-fair leaders who avoid managerial duties, are reluctant to take actions and are not always there when needed. The first two forms of leadership can be positive forms of leadership when undergoing a change and dealing with workplace conflict. The laissez-faire style would leave co-workers to work out problems on their own. This would most likely not be a positive way to deal with conflict as long-term problems can lead to reduced productivity.

\section{From Domination to Partnership}

Author Riane Eisler discusses the idea of partnership vs. dominator models and the way society has changed. Our changing world calls for an evolution to partnership-based management and leadership. In the past, a dominator model was more prevalent when more men were in the workforce. This resulted in male dominance with masculine values and activities associated with toughness, strength, conquest and domination. 
Today's society calls for a partnership or more "nurturing" way of management and leadership. Women and men managers both are adopting a more empathic, nurturing management style, which is a shift from a dominator to a partnership model. The workforce is filled with dual career couples, where both men and women are taking on the work role and the family role and facing similar issues.

\section{RATE OF CHANGE IN ORGANIZATIONS}

The rate of change is going up for most companies and as the rate of change increases a company needs to learn how to deal with change and adapt and it needs to be done quickly to keep up. This article deals with the sense of urgency changes bring and the fact that employees can be rather complacent about making the changes happen. People like to shift the blame and say the problems are in other departments or it is their boss who is the problem. Other times people drag their feet because they are afraid to take the next step. Managers can deal with this by making sure they know what is going on and by being seen. Managers need to deal with the naysayers because these are the workers who convince other to be stagnant.

\section{Positive Organizational Change}

John Illingworth suggests in this article that positive organizational change is project driven and led by competent project leaders. Leadership is the key. Research done by the American Management Association revealed that leadership was rated 98.1 percent as the most important factor in change management. Competition is forcing companies to make big changes in their thinking, strategies, products and services. This article discusses the fact that many times when companies are not doing well they lay off people as a means to save money. Here they suggest initiating projects and project teams to increase productivity and reduce waste, thus reducing layoffs, which only dumps the burden on those, left and depletes morale.

\section{Making Change Work For Real}

Making Change Work - for Real outlines a four-step process for managers to follow to make change work. Step 1 is referred to as Catalyzing and refers to starting with change from the top. An example was given of how the CEO wanted the change but did not bother to show up to the meeting he set up to announce it - the result - the change never happened. Step 2 is Diffusing and refers to communicating the vision. This means making sure senior management communicates and provides a unified front. When one person accepts the change it is much easier for the next person to accept it. Step 3 is Paying People to play which refers to rewards and they suggest rewarding groups instead of individuals and include social recognition, human capital, learning, marketability and power. Step 4 is Training. People are more likely to accept change if they are confident in their new roles, skills and responsibilities.

\section{Sustaining Commitment to Change}

Many times great people develop great ideas for change and these ideas are put into motion but they are never achieved. This article discusses how to sustain the commitment to change. The first tip is to have a strong leader, someone important enough that everyone within the organization will take them seriously. It is also critical to make sure those involved have the time to see the project through - they cannot become bogged down with too many responsibilities. Communication is key - keep people informed by making the changes, progress and success stories visible. Culture must be taken into consideration along with structure, systems, education, resources, people support and a means to measure process. All these are needed to sustain change. 


\section{Change Agent}

Herr the literature focuses on the job of the CEO during organizational change. It points out that CEO's are the starter of change and the stopper of change and as such they need to stay ahead of change if they want to achieve the results they expect. The article points out the five main reasons for failure when initiating change (bad decision, poor leadership, unclear results, unengaged workers, and an invisible CEO) and then goes on to give five key actions to achieve success when implementing change. These include determining which strategic change to implement, choosing the right leaders, resources, etc., defining the expected results, keeping the workforce engaged, and has the CEO staying visible throughout the process. The CEO needs to be the Chief Change Agent.

\section{Effective Change Management}

Phil Merrell lists six activities, which really influence overall success for change management. These include "Leading" which involves making sure management has a clear vision on the intent and purpose of the change and has support from the top. The second is "Communicating" because communication helps change because it fosters understanding and motivates employees. The third is "Learning" which involves making sure employees are trained and have the knowledge and skills necessary to adapt to the changes. The fourth is "Measuring" or using a set of metrics to assess whether the goals have been achieved both during and after the change. The fifth is "Involving" which means asking the opinion of the people affected by the change, whether they be employees or customers. Involving tends to make the changes easier to implement. The last is "Sustaining" which involves the company and/or the managers putting in place the capabilities needed to ensure the change sticks which may include updating processes, policies, technology and even structures to support the change.

\section{Organizational Change and High-Performance Team}

Here the literature focuses a consultant Gale Mote, who assisted with organizational change for a company making a transition to high-performance work teams. She has gone through these changes with many different companies. She writes that when adults tend to ask the same questions repeatedly it is because they don't like the answer. Employees need to know they will receive the support they need to make the change such as training and be able to test their skills. Trust is also a big issue. Employees do not always trust the whole truth is coming from their employer during a change, so be honest, fair and keep your commitments. Fear is another big issue. People are afraid they will not be successful in their new roles. It is important to provide training and coaching. Sometimes people cannot adapt and Gale suggests, "don't let those who don't get it and won't get it stay. Sometimes managers have to make difficult decisions and let people who go cannot accept the change.

\section{Affect and Leadership during Radical Organization Change}

This literature reviews a field study performed at a government agency undergoing a major change. Employees assessed their manager's leadership behavior and reported on their own behavioral responses. The study focused on transformational leadership and affect-focused leadership and it was surprisingly determined that affect-focused leadership was more beneficial in this study because this type of leadership helps employees cope with change to prevent any negative outcomes, whereas transformational leadership focuses on a clear vision along with enthusiasm and motivation. They study suggests that without a positive effect on employees any change is doomed. It's all about leaders making employees view the change in a positive way so that they want the change to take place. 


\section{LEADERSHIP AND EMPLOYEES REACTIONS TO CHANGE}

This study reviewed the personalities of leaders and employees and how their personal characteristics have a meaningful impact on the change process. The study found a managers' self-awareness was linked to improved performance. Managers themselves are sometimes not in favor of the change and this attitude can affect whether employees welcome the change or fight the change. HR departments not only need to work with resistant employees but with resistant managers as well. Leaders need to have "charismatic" leadership behaviors to encourage all those to embrace the change. This study suggests that not only managers but HR must play a large role in creating a culture to welcome the change such as workshops, training session and group and individual communication.

\section{Leadership in Turbulent Times}

David Pardley, a consultant at the Institute of Leadership and Management examines in a article why leadership is important during times of organizational change. He distinguishes the difference between leadership and management with the leadership role having more of a "doing the right thing" belief and the management role having a "doing it right" belief. A classic way of thinking for management would be to make sure that we get things right each and every time versus a focus of thinking of ways to be more creative and divergent and taking advantage of new opportunities - which is where leadership comes in to play. Leadership involves communicating a clear vision and having a plan, inspiring the right behavior, being a role model, motivating, and empowering those under our leadership.

\section{Leadership Skills and Organizational Change}

Many leadership skills are extremely important to both an organization as well as employees throughout an organizational change. Of greatest importance, though, would be communication at all levels, as it provides a means of communication for employees to ask questions and receive feedback throughout the transition of an organizational change. Additionally, the article speaks primarily to the various competencies and skills necessary to effectively manage the organizational change, and one of which is stated as the deficiency of knowledge for various aspects of the organization. As a leader, individuals must be (somewhat) knowledgeable in most areas of an organization, and by being a bit less knowledgeable in some areas than others, it leaves room for question from the employee at how they may effectively manage this change, or what they may do if a leader is not knowledgeable in the area they need assistance. Leadership skills and qualities are one of the largest areas of an organizational change, to which leaders must be more proficient in these qualities than unknowledgeable in others to help employees and drive the organization towards success.

\section{Leadership and Managing Organizational Change}

This article speaks primarily to the leadership qualities necessary to manage organizational change, as well as the pace to which organizations are changing and leaders must keep up. In many organizations, change is at a rapid pace, and it can be difficult for some leaders to keep up to maintain the change and continue to drive the organization towards success. In addition, the article speaks to the different methods and aspects to which leaders and senior management must maintain to benefit employees and support them in their roles. If a leader has a difficult time keeping up with the change, it can be incrementally difficult to support employees in the change, as the organization is moving and changing at such a rapid pace. It is in times such as these to which employees must effectively communicate and take charge of their role to help employees in managing the change effectively. 
Benefits of a Successful Organizational Change

Many organizations base benefits off reward systems set by the organization, though organizational change can bring different aspects or outcomes to this type of system. Based on the article, one of the best ways of engaging employees and helping promote success through an organizational change is through a "win-win" scenario, to which employees receive rewards based on their performance post organizational change. Additionally, many employees question their role clarity and job security throughout organizational changes, which can provide some areas of fear or discomfort for employees. By enlisting rewards systems, leaders are able to gain the commitment of employees and provide benefits to employees as well, while employees are actively engaged in their roles to help the organization in its change.

\section{CONCLUSION}

Change is inevitable it happens daily all around us whether we like it or not. As humans, we tend to fear and steer away from change as much as possible. Employees do not like change but if implemented well it will help an organization. Change is inevitable and leaders must embrace it if they want to succeed.

\section{REFERENCES}

1. Ahn, M. J., Adamson, J. S., \& Dornbusch, D. (2004). From Leaders to Leadership: Managing Change. Journal of Leadership \& Organizational Studies, 10(4), 112- 123. doi: 10.1177/107179190401000409

2. Appelbaum, S. H., Lefrancois, F., Tonna, R., \& Shapiro, B. T. (2007). Mergers 101 (part two): training managers for culture, stress, and change challenges. Industrial \& Commercial Training, 39(4), 191-200. doi:10.1108/00197850710755113

3. Appelbaum, S. H., St.Pierre, N., \& Glavas, W. (1998). Strategic organizational change: The role of leadership, learning, motivation and productivity. Management Decision, 36(5/6), 289.

4. Barrett, D. J. (2002). Change communication: using strategic employee communication to facilitate major change. Corporate Communications: An International Journal, 7(4), 219-231. doi: 10.1108/13563280210449804

5. Battilana, J., Gilmartin, M., Sengul, M., Pache, A.-C., \& Alexander, J. A. (2010). Leadership competencies for implementing planned organizational change. The Leadership Quarterly, 21(3), 422-438. doi: 10.1016/j.leaqua.2010.03.007

6. Boga, I., \& Ensari, N. (2009). The Role of Transformational Leadership and Organizational Change on Perceived Organizational Success. Psychologist-

7. Manager Journal (Taylor \& Francis Ltd), 12(4), 235-251.

8. doi:10.1080/10887150903316248

9. Borbidge, D. J. (2006). Culture Change. (cover story). Industrial Safety \& Hygiene News, 40(1), 50-52.

10. Bourque, R. J. (2001). Changing for the better isn't as easy as it sounds. New Hampshire Business Review, 23(16), 19.

11. Caldwell, R. (2003). Models of Change Agency: a Fourfold Classification. British Journal Of Management, 14(2), 131-142. doi:10.1111/1467-8551.00270

12. Chaleff, I. (2008). Let the Middle Lead. Leadership Excellence, 25(2), 10.

13. Clement, R. W. (1994). Culture, leadership, and power: The keys to organizational change. Business Horizons, 37(1), 33. 
14. Doucet, O., Poitras, J., \& Chênevert, D. (2009). The impacts of leadership on workplace conflicts. International Journal Of Conflict Management (Emerald), 20(4), 340-354. doi:10.1108/10444060910991057

15. Eisler, R. (1995). From domination to partnership: The hidden subtext for organization change. Training \& Development, 49(2), 32.

16. Gilley, A., Dixon, P., \& Gilley, J. W. (2008). Characteristics of leadership effectiveness: Implementing change and driving innovation in organizations. Human Resource Development Quarterly, 19(2), 153-169. doi: 10.1002/hrdq.1232

17. Heffes, E. M. (2009). You Need Urgency Now!. Financial Executive, 25(1), 20.

18. Illingworth, J. (2001). PROJECT LEADERSHIP can deliver positive change. New Zealand Management, 48(7), 30.

19. Making Change Work--for Real. (2003). HR Focus, 80(1), S1.

20. Maurer, R. (2005). Sustaining Commitment to Change. Journal For Quality \& Participation, 28(1), 30-35.

21. Meinhard, C. (2012). Chief Change Agent. Leadership Excellence, 29(6), 11.

22. Merrell, P. (2012). Effective Change Management: The Simple Truth. Management Services, 56(2), 20-23.

23. MOTE, G. (2013). Just because you said it, doesn't mean they got it. Corridor Business Journal, 10(17), 14.

24. Myeong-Gu, S., Taylor, M., \& Hill, N. (2007). The Role of Affect and Leadership During Radical Organization Change. Academy Of Management Annual Meeting Proceedings, 1-6. doi:10.5465/AMBPP.2007.26530920

25. Oreg, S., \& Berson, Y. (2011). Leadership and Employees' Reactions to Change: The Role of Leaders' Personal Attributes and Transformational Leadership Style.

26. Personnel Psychology, 64(3), 627-659. doi:10.1111/j.1744-6570.2011.01221.x

27. Pardey, D. (2007). Leadership in turbulent times. Strategic HR Review, 6(5), 16-19.

28. Pfeffer, J., \& Veiga, J. F. (1999). Putting people first for organizational success. Academy of Management Perspectives, 13(2), 37-48. doi: 10.5465/ame.1999.1899547

29. Will, M. G. (2015). Successful organizational change through win-win. Journal of Accounting \& Organizational Change, 11(2), 193-214. doi: 10.1108/jaoc-06-20130056 